\title{
Компания Delson Technology: широкий выбор памяти для различных приложений
}

\author{
Рассказывает генеральный директор \\ компании Delson Technology Э. Чу
}

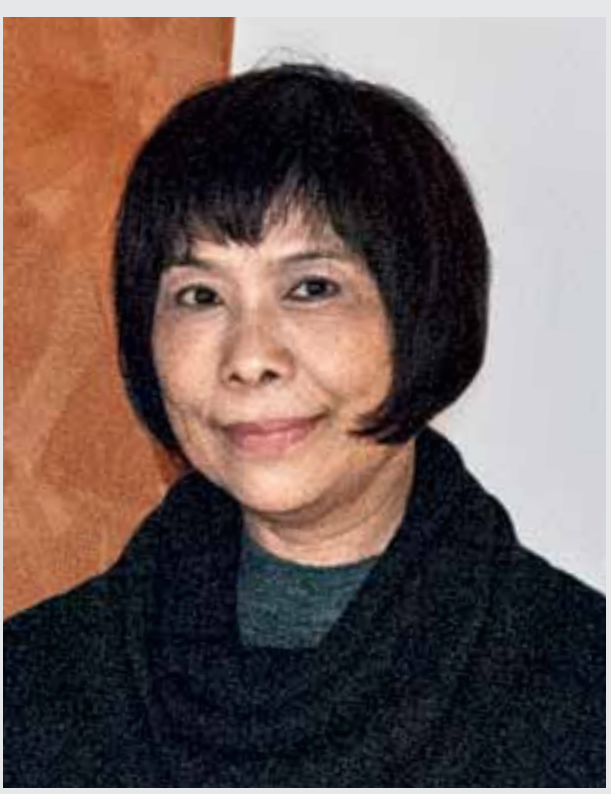

\begin{abstract}
Компания Delson Technology Corporation (DTC) (Тайвань) специализируется на выпуске микросхем и модулей памяти различных типов. Компания еще молодая (основана в 2011 году), но уже имеет довольно большое число клиентов. Широкий ассортимент и высокое качество продукции позволяют компании в ряде областей успешно конкурировать с крупными производителями памяти, такими как Samsung, Micron, Hynix. C 2014 года Delson Technology работает и на российском рынке. На выставке electronica 2018 в Мюнхене (Германия) генеральный директор компании Delson Technology Энни Чу (Annie Chou) рассказала нам об основных направлениях и особенностях деятельности компании, в том числе в России.
\end{abstract}

Госпожа Чу, какую продукцию и услуги предлагает сегодня ваша компания?

Компания Delson Technology выпускает широкую линейку микросхем и модулей памяти. Среди них оперативная память различных типов (DDR, DDR2, DDR3, DDR4 и др.), оперативная память в промышленном исполнении (I-Tеmp) (тоже различныхтипов), рассчитанная на работу в широком диапазоне температур (от -40 до 85, 95 или $105^{\circ} \mathrm{C}$, в зависимости от типа памяти), и энергонезависимая память еммС и Nand Flash. В каждой категории представлены изделия с различным объемом памяти. Кроме того, мы можем производить микросхемы памяти «под заказ», в том числе для высоконадежных систем. Еще одно направление нашей деятельности - услуги по тестированию микросхем памяти. Delson Technology также предлагает различные ОЕМ-услуги: нанесение логотипа с помощью лазера, изготовление специальных модулей оперативной памяти, ремонт продукта или его замена и др.

Память, поставляемая нашей компанией, может использоваться во многих приложениях, как потребительских, так и промышленных: цифровых телевизорах, телевизионных приставках, цифровых камерах, видеокартах, твердотельных жестких дисках (SSD), навигаторах, спутниковых ресиверах, кабельных модемах, ADSLроутерах, системах промышленной автоматизации, POSтерминалах и многих других.

Каковы особенности и преимущества Delson Technology по сравнению с конкурентами?

Как говорится, конкуренты хороши, но мы лучше. Если же говорить серьезно, можно отметить несколько моментов. Во-первых, мы являемся фаблесс-компанией. Это позволяет нам быть гораздо более гибкими в выпуске изделий, мы можем обеспечить более короткие сроки вывода новых устройств на рынок - обычно у нас они составляют от четырех до шести недель. Во-вторых, цена нашей продукции ниже, чем у конкурентов, опять-таки за счет того, что нам не нужно нести высокие расходы, связанные с содержанием собственного завода. В-третьих, команда наших специалистов может очень гибко реагировать на запросы рынка - как только появляются новые потребности и тенденции, мы сразу же переключаемся на разработку соответствующих продуктов и стараемся 
вывести их на рынок в кратчайшие сроки. Крупные компании работают, как правило, гораздо медленнее, так как они вынуждены заниматься всеми проблемами, связанными с организацией собственного производства. Таковы три основных фактора нашего успеха.

Кроме того, важный момент - высокое качество нашей продукции. Оно обеспечивается изготовлением памяти на эффективных предприятиях, оснащенных современным высокотехнологичным оборудованием, с тщательным контролем качества в соответствии с высокими стандартами на всех этапах производственного процесса. Delson Technology тесно сотрудничает с ведущими разработчиками и производителями DRAM-памяти, такими как Promos Technologies (Тайвань). Благодаря высокому качеству у нас практически нет проблем, связанных с отказами наших изделий. Так, за весь период работы Delson Technology в России (с 2014 года) не было ни одного случая возврата нашей продукции по причине заводского брака. Еще одно преимущество компании - возможность продолжения поставок микросхем памяти в течение длительного времени. Также необходимо отметить, что мы предлагаем помощь в выборе продукта, обеспечиваем гарантийный ремонт и техническую поддержку. И, разумеется, компания Delson Technology гарантирует своим клиентам крепкие долговременные деловые и личные связи и обоюдную выгоду, базирующуюся на доверии, качестве и профессионализме.

\section{Какую продукцию вы сегодня поставляете в Россию?}

Изначально мы поставляли российским потребителям в основном DDR-память, но сейчас хотим расширить также объемы продаж памяти еММС и Nand Flash. Основной акцент мы делаем на память, работающую в промышленном температурном диапазоне (I-Temp), поскольку здесь, по нашему мнению, у нас есть ряд преимуществ перед конкурентами. Также мы планируем начать поставки в Россию микросхем памяти типа DDR4, которые мы начали выпускать сравнительно недавно. Поскольку они обладают увеличенным быстродействием по сравнению с микросхемами DDR3, то, по нашему мнению, будут очень важны для приложений, где необходима высокая скорость обработки данных.

В чем, на ваш взгляд, особенности российского рынка?

Российский рынок развивается, но работа на нем, к сожалению, зачастую происходит медленнее, чем хотелось бы, требуется длительное время, чтобы начать деятельность. Так, после демонстрации образцов нашей продукции приходится довольно долго ждать момента, когда можно будет начать их поставки. Тем не менее мы считаем российский рынок очень привлекательным 
и видим для себя большие перспективы работы в России. Мы совместно с нашим дистрибьютором - компанией ЗАО "Конкур электрик» - стремимся предоставить российским потребителям продукцию, которая имеет преимущества по сравнению с той, что была им доступна до сих пор. Они хорошо знают память, выпускаемую такими крупными компаниями, как Samsung, Micron, Hynix, но мы предлагаем аналогичные и не менее качественные изделия на более выгодных условиях. Пока основная проблема в том, что мы, как молодая компания, еще не очень широко известны, в том числе на российском рынке, но с помощью нашего дистрибьютора мы надеемся изменить эту ситуацию и успешно конкурировать с крупными производителями памяти, увеличивая поставки нашей продукции.
Каковы ваши впечатления о выставке electronica 2018?

Впечатления самые положительные. На выставке представлено огромное количество новых интересных разработок, технологий и продуктов. У нас не было своего стенда на этой выставке, поскольку мы ставили своей целью не столько представить нашу компанию, сколько как можно более подробно познакомиться с деятельностью других разработчиков и производителей. Мы нашли среди показанного на выставке electronica 2018 много полезного для себя и планируем использовать полученную информацию для развития нашей компании. Возможно, на следующей выставке мы организуем и свой стенд.

Спасибо за интересный рассказ.

С Э. Чу беседовап Ю. Ковалевский

\section{НОВЫЕ КНИГИ ИЗДАТЕЛЬСТВА «ТЕХНОСФЕРА»}

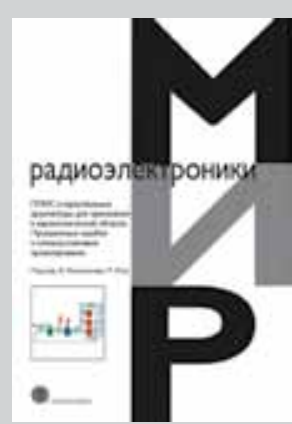

Цена 920 руб.

\section{ПЛИС И ПАРАЛЛЕЛЬНЫЕ АРХИТЕКТУРЫ} ДЛЯ ПРИМЕНЕНИЯ

\section{В АЭРОКОСМИЧЕСКОЙ ОБЛАСТИ.} ПРОГРАММНЫЕ ОШИБКИ И ОТКАЗОУСТОЙЧИВОЕ ПРОЕКТИРОВАНИЕ Под ред. Ф. Кастеншмидт, П. Реха Издание осуществпено при поддержке АО "Конструкторско-технопогический центр "ЭЛЕКТРОНИКА"

В книге приводится понятие устранимых ошибок, возникающих в ПЛИС типа ППВМ (FPGA - Field Programmable Gate Array) и графических процессорах. Рассматриваются радиационные эффекты в ПлИС, отказоустойчивые методы для Плис, применение серийно выпускаемых ПлиС в авиации и космонавтике, экспериментальные данные о воздействии радиации на ПлИС, встроенные в ПлИС процессоры под воздействием радиации и внесение ошибок в ПлИС. Поскольку специализированная архитектура параллельной обработки, как в случае графического процессора, стала более востребованной в авиации и космонавтике благодаря высоким вычислительным возможностям, также приводятся результаты анализа поведения графического процессора под воздействием радиации.

Книга будет полезна не только инженерно-техническим работникам, занимающимся применением серийно выпускаемых ПЛИС в авиации, космонавтике, приборостроении для транспорта и других критически важных областях народного хозяйства, но и магистрантам, обучающимся по направлению подготовки 11.04 .04 «Электроника и наноэлектроника», а также аспирантам, проходящим обучение по направлению подготовки 11.06 .01 «Электроника, радиотехника и системы Связи». 